\title{
Business Resilience: Managing the Business Uncertainty during High Times of Economic Slowdowns with Special Reference to COVID-19
}

\author{
Sunil Sharma \\ Co-founder, SKS Corporate Advisors, India. \\ Fellow, The Institute of Company Secretaries of India, New Delhi, India.
}

\begin{abstract}
A pandemic breaks out and spreads to the geographies and regions of the entire world. Increased infections force governments to bring in lockdowns locking almost every activity. The restrictions are put on the movement of humans and goods. Supply lines are badly affected. The demands are not met due to disrupted supply chains at the beginning of such a breakout. And, consumer demand gets badly affected as we move through uncertain times while fighting and overcoming such unfortunate times. This paper examines the relevance of business resilience and management outlooks for ensuring sustainable business models coupled with community-oriented service models.
\end{abstract}

Keywords: Business Resilience, Crisis Management, Pandemic, Business in Pandemic, COVID-19, Future Businesses

Uncertainty brings in disturbed demands patterns and behaviour of the consumers which forces the businesses to struggle to maintain their business activities and business continuity becomes an unrealistic scene as they progress through the times of uncertainty and business slowdowns. Businesses need to explore, design and execute innovative approaches to make their businesses resilient and adaptive to the changed business scenario.

Important thing first, what do we need to know about business resilience?

Business resilience is the ability of a business to innovate, change and adapt to the unexpectedly uncertain business environment.

As the definition above tells us, there are unexpected events that cause uncertainty in business activities. And, businesses need to be prepared to change even when they don't want to change. Innovative, sometimes unexpectedly innovative business patterns and outlooks need to be designed and executed to survive the challenging times. 


\section{What do we mean by the 'unexpectedly innovative' business patterns or plans?}

Unexpectedly innovative business patterns are the results that businesses would have not been trying to achieve if the uncertainty didn't bother them. In a normal business scenario, when it is easier to earn a certain level of revenue by doing a certain set of activities, it is unnecessary to innovate if the same is not needed expressly by the businesses.

When a business is trying to overcome an economic slowdown and all the existing business plans and strategies are not helping, some radical changes need to be tweaked in the business strategy to resiliently survive the uncertain business outlook.

The Five Stars hotels introducing home delivery is an example of the 'unexpectedly innovative' business pattern ${ }^{1}$. In normal business scenarios, no Five Stars hotel will even bother to home deliver their super classy foods but in the recently unfolded time of COVID-19, there were many Five Stars hotels who introduced home delivery of their foods and beverages to save their business existence and human resources.

Another example is the non-FMCG companies introducing hand sanitizers during pandemic times ${ }^{2}$. This became even more watchful when even the FMCG and some pharmaceuticals weren't planning (actually) to launch hand sanitizers had there not been the COVID-19 breakout.

An airline company launching an air ambulance services subsidiary in the midst of movement restrictions caused by pandemic lockdown is another example of a radical tweak in the business strategy. Another example could be of an airline company launching a portable ventilation device ${ }^{3}$.

Insurance companies launching short to medium range period COVID-19 special covers are another example of business continuity stimulus.

\section{So, what is the plan to innovate?}

We have observed that there has been a similarity of objectives of the companies and the objectives of the newly launched subsidiary or products. An airline company launching an air ambulance service is well understandable, as the assets that an air ambulance service needs are well possessed by the holding airlines company.

With years of experience in insurance products, the insurance companies have coined COVID specific covers evaluating their risk probability outlooks.

\footnotetext{
1 5-star hotels go the Zomato-Swiggy way! Launch home delivery, takeaway services. https://www.businesstoday.in/latest/corporate/story/5-star-hotels-go-the-zomato-swiggy-way-launchhome-delivery-takeaway-services-257261-2020-05-04

2 New players enter hand sanitiser biz, consolidation certain, say FMCG firms. https://www.businessstandard.com/article/companies/new-players-enter-hand-sanitiser-biz-consolidation-certain-say-fmcgfirms-120092301068_1.html

3 Airlines pitch in amid Covid: IndiGo flies plasma, SpiceJet launches portable ventilator support. https://www.hindustantimes.com/india-news/airlines-pitch-in-amid-covid-indigo-flies-plasma-spicejetlaunches-portable-ventilator-support/story-ucqRwLb5mcq3jdCCZJhMhL.html
} 
The F\&B divisions of five-star hotels were capable of serving the home delivery demands with the available personnel who otherwise had no other work to do in the hotels sans guests.

\section{Factors affecting crisis-time business resilience strategy}

There are many factors present in the internal and external business environment that have a direct or indirect bearing on any business innovation during a crisis time. The business managers and the strategy planners need to undertake a careful analysis of these factors. Every business firm has some industry-specific and firm-specific factors built into its business environment. With the weaknesses and strengths, a firm has, business planners, need to carefully observe opportunities and threats coming from the external business environment a firm operates in.

In the present case of the COVID-19 pandemic, the firms exampled above had done the same. Their planners were promptly analysing their internal as well as external business environment. They identified the strengths and weaknesses along with opportunities and threats present in their business environments. They matched and correlated all the factors to formulate their crisis response as well as business continuity plans.

From the above-mentioned cases, an airline had enough infrastructure i.e. airplanes that could swiftly be converted into air-ambulances as per demand outlook. Their flight crew and the on-ground services could easily be used by the newly floated service.

The same holds good for the example of five stars hotels delivering foods in pandemic times. They needed to introduce just a home delivery function, and the rest of everything that they needed was there in their F\&B sections and idle human resources.

The firms, exemplified in this article, had one common thing that helped them to respond to the unfolded crisis. And, that was, their planners were quick enough to take account of their SWOT $^{4}$ factors.

\section{Tapping the ad-hock diversification}

During the crisis time, especially the COVID-19 pandemic, there were firms, big and small, that were preparing them to cater to the sudden created demand. For example, states and countries were declaring lockdowns and demand for hygiene-related products shot up. The sanitizer shelves went out of stock and the media started highlighting it.

The business planners were taking note of their existing production capacities and were doing everything to scale up their production and supply. Majority of FMCG firms

\footnotetext{
4 SWOT stands for strengths \& weaknesses forming an internal business environment, and opportunities
} $\&$ threats forming an external business environment. 
now sanitizer as a product component in their market offering. Even the firms from outside the FMCG segment introduced sanitizers in the market.

Some firms came with the idea of getting contract manufacturing of the in-demand hygiene-related products. And, they got their contract manufactured products marketed under their brand name.

\section{Shifts in marketing strategies}

Crisis time like COVID-19 also provided many firms opportunities to consolidate their brand values. Many pharmaceutical companies ran advertising campaigns underlining the time and their offerings for which they have been there in the market, and thus promoting themselves as a healthcare partner in the general health of the communities.

From less known to unknown health supplements came into the market and were enticing social media users ${ }^{5}$. Just for the sake of increased immunity, nearly everything was getting a sale. Another real-life case can be of companies promoting their products to be helpful in increasing or maintaining human immunity ${ }^{6}$. Some air fan brands were seen in video ads that their fans come with blades that don't attract dirt and bacteria. The same fan which was earlier promising cool air is now claiming to blow healthy bacteria-free air.

The canned juices which were earlier suggesting that they were refreshing are now highlighting how they can help people get an increased immunity.

\section{What next?}

Businesses across nations are using newer ways of working, work from home is one of the key ways. Web technologies, video conferencing, and other tech-enabled remote working are changing the way businesses do business. It's not just COVID-19 pandemic that forced this to happen, but we have started sensing even more explicit threats to humanity, global warming and upcoming challenges to human existence on earth in the coming decades.

The automobile sector has leaped into designing and manufacturing electric vehicles as a contribution to preserving the environment in their efforts to reduce their dependence on the fossil-fuelled vehicles market. Electricity generators manufacturing companies are foraying into manufacturing solar panels and plants. Even the water purifiers manufacturers are addressing issues like increasing the TDS acceptance level into purified water to save on water, an essential to human life.

Business resilience isn't all about getting more business and revenues, but it has to be understood in the context of sustainability and support for human life, the

\footnotetext{
5 Wagner, D.N., Marcon, A.R. \& Caulfield, T. "Immune Boosting" in the time of COVID: selling immunity on Instagram. Allergy Asthma Clin Immunol 16, 76 (2020). https://doi.org/ 10.1186/s 13223-020-00474-6 6 Covid impact: Brands launch immunity boosting ad campaigns to woo consumers.

https: / / www.livemint.com/industry/advertising/ads-of-immunity-boosting-products-woo-customersamidst-pandemic-1 1591954040996.html
} 
environment, and natural resources. A company's social acceptance is now measured in its efforts to put forward a sustainable approach to doing business, paying full attention to the community resources and ecological balance.

The modern-day enterprises will now work even more closely with governments, communities, and civil society organizations to establish foundations of resilience, the sustainable development of their customers, employees, community, investors, and the planet as a whole.

The time has passed when these things were termed as theoretical approaches and just moral education lessons, but the time has come when the businesses will remain sustainable only when these things are taken care of.

\section{References}

1. Dahles, H., \& Susilowati, T. P. (2015). Business resilience in times of growth and crisis. Annals of Tourism Research, 51, 34-50.

2. Gilpin, D. R., \& Murphy, P. J. (2008). Crisis management in a complex world. Oxford University Press.

3. Sharma, P., Leung, T. Y., Kingshott, R. P., Davcik, N. S., \& Cardinali, S. (2020). Managing uncertainty during a global pandemic: An international business perspective. Journal of business research, 116, 188-192.

4. Wagner, D.N., Marcon, A.R. \& Caulfield, T. "Immune Boosting" in the time of COVID: selling immunity on Instagram. Allergy Asthma Clin Immunol 16, 76 (2020). https://doi.org/10.1186/s13223-020-00474-6

5. 5-star hotels go the Zomato-Swiggy way! Launch home delivery, takeaway services. https://www.businesstoday.in/latest/corporate/story/5-star-hotelsgo-the-zomato-swiggy-way-launch-home-delivery-takeaway-services-2572612020-05-04

6. New players enter hand sanitiser biz, consolidation certain, say FMCG firms. https://www.business-standard.com/article/companies/new-players-enterhand-sanitiser-biz-consolidation-certain-say-fmcg-firms-120092301068_1.html

7. Airlines pitch in amid Covid: IndiGo flies plasma, SpiceJet launches portable ventilator support. https://www.hindustantimes.com/india-news/airlinespitch-in-amid-covid-indigo-flies-plasma-spicejet-launches-portable-ventilatorsupport/story-ucqRwLb5mcq3jdCCZJhMhL.html

8. Covid impact: Brands launch immunity boosting ad campaigns to woo consumers. https://www.livemint.com/industry/advertising/ads-of-immunityboosting-products-woo-customers-amidst-pandemic-1 1591954040996.html 